\title{
Lessons Learnt From Typhoons Fitow and In-Fa: Implications for Improving Urban Flood Resilience in Asian Coastal Cities
}

Faith Chan ( $\sim$ faith.chan@nottingham.edu.cn )

University of Nottingham Ningbo China https://orcid.org/0000-0001-6091-6596

\section{Xinbing Gu}

University of Nottingham Business School China

\section{Yunfei Qi}

University of Nottingham Ningbo China Faculty of Science and Engineering

Dimple R. Thadani

University of Nottingham Business School China

\section{David Yongqin Chen}

CUHKS: The Chinese University of Hong Kong - Shenzhen

\section{Xiaohui Lu}

University of Nottingham Business School China

\section{Lei Li}

University of Nottingham Ningbo China Faculty of Science and Engineering

James Griffiths

National Institute of Water and Atmospheric Research Christchurch Office

\section{Fangfang Zhu}

University of Nottingham Ningbo China Faculty of Science and Engineering

\section{Jianfeng Li}

Hong Kong Baptist University Faculty of Social Sciences

\section{Wendy Y. Chen}

The University of Hong Kong Department of Geography

\section{Short Report}

Keywords: Typhoon, Climate Change, Resilience, Big Data, Social Media

Posted Date: September 7th, 2021

DOI: https://doi.org/10.21203/rs.3.rs-799579/v1 
License: (c) (i) This work is licensed under a Creative Commons Attribution 4.0 International License. Read Full License

Version of Record: A version of this preprint was published at Natural Hazards on September 21st, 2021. See the published version at https://doi.org/10.1007/s11069-021-05030-y. 


\section{Abstract}

Frequent typhoons are significantly affecting the coastal cities via intensive rainstorms, tidal surges and strong wind. Natural factors such as climate change and global sea-level rise come alongside anthropogenic factors such as rapid urbanisation and land use/land cover change leading to detrimental consequences such as urban floods. This short communication offers various lessons learnt by Ningbo municipality from two strong typhoons that hit the city directly, namely "Fitow" in 2013 and "In-Fa" in 2021. On the one hand, the usage of "Big Data" and "Social Media" for bettering "Preparation" and "Prevention" reduced flood impacts significantly. On the other hand, the implementation of "Flood Insurance" speed up the "Recovery" processes. The successful "Preparation", "Response" and "Recovery" helped Ningbo to enhance its flood resilience, and thus substantial impacts of injuries, household damages and associated economic loss were avoided. These three key terms should be heeded in typhoon/flood governance in which various stakeholders are involved with, and be incorporated into the city's long-term strategic development plans to merge with the climate actions towards 2030s and beyond. This will be vitally important in reducing climatic hazards and improving coastal flood resilience under the future climatic uncertainties in Asian coastal cities. (196 words)

\section{More Upcoming Typhoons And Extreme Storms}

The coastal regions in East Asia, such as the East and South coast of Chinese provinces including Zhejiang, Fujian and Guangdong, are experiencing particularly frequent typhoon disturbance and facing great flood risk due to rapid urbanisation and extensive development on the low-lying coastal plain with little topographic relief and thus are prone to floods (Wang, 2018). For example, the prospect of climate change will likely exacerbate the temperature increase of seawater and increase the magnitude of lowpressure systems associated with tropical cyclones in the West Pacific in the upcoming future (Griffiths et al., 2019). This will impact the deltaic region of the Yangtze River and the Pearl River, two most important economic centres and logistic hubs in southeast China, where many major cities like Ningbo, Shanghai, Hong Kong, Shenzhen and Guangzhou are located (Chan et al., 2019). The Hong Kong Observatory (Hong Kong Special Administrative Region' Meteorological Office) recorded over 40 typhoon visits in the Pearl River Delta in the 1990s and 2000s, and expected typhoons, storm surges and intensive rainstorms will visit the region more often in ensuing decades (Woo and Wong, 2010).

Obviously, the probability of urban surface floods in coastal cities in southeast China is increasing due to the following factors: (1) more frequent and intensive rainstorms that exceed the capacity of the current land drainage system (Qi et al., 2021); (2) surge-enhanced backlash of seawater that might affect land drainage systems; (3) direct inundation by extreme tidal changes via storm surge (Chan et al., 2021); and (4) the coactive impacts of these factors. In addition, global sea-level is predicted to rise by 0.2 to 0.4 metres over the next 50 years (Hallegatte et al., 2013), which would be as much as 1.2 to 1.8 metres by 2100 under various economic development scenarios and climate change models (Church and White, 2011) (Verheggen et al., 2014) (Nerem et al., 2018). Locally, the Hong Kong Observatory and the China's State Ocean Bureau estimated an annual sea-level rise rate at 2.1-2.3mm/year from the 1950s up to now, 
which means we can expect about 0.6 to 0.7 metres increase if nothing changes substantially (Chan et al., 2021). These dual effects would bring further challenges to flood governance.

This short communication aims to illustrate how Ningbo managed to minimise injuries and damages in two Typhoon events, namely "Fitow' in 2013 and "In-Fa" in 2021, and meanwhile to enhance the city's climate resilience by integrating Climate Action Plans (focusing on Preparation, Prevention and Recovery) with long-term strategic development plans. The successful experiences of Ningbo should be heeded in typhoon/flood governance of many other Asian coastal cities prone to flooding.

\section{Two Typhoons (Fitow And In-fa) In Ningbo - Consequences And Impacts}

\subsection{Ningbo - background}

Ningbo is a typical coastal city located in the east coast of China (Figure 1), with immense annual rainfall ( $50 \%$ of the mean annual rainfall at about $1500 \mathrm{~mm}$ ) during typhoon season that runs from June to October annually. By contrast, rainfall in dry season (November to February) normally ranges from 250 to $300 \mathrm{~mm}$ annually. Water resources management in Ningbo focuases on not only the capacity of dams and reservoirs to prevent the outburst of dams under storms, but also the provision of adequate water resources during dry season (Griffiths et al., 2017). The majority of the city's $9816 \mathrm{~km}^{2}$ land area is flat, with elevation ranging from 2 to 10 metres above-sea-level, whereas the tidal range is from 1.6 to 5.8 metres. Traditionally, Ningbo is equipped with a land drainage system that can only handle rainfall events at 1-in-1 to 1 -in-5 years return period. This means the city is at high risk during the typhoon period, as intensive stormwater is difficult to be discharged quickly through the drainage system and three tidal rivers (Yao River, Fenghua River, and Yong River), particularly when the surges are concurrently raising the river level to decrease the runoff capacities (Griffiths et al., 2020). Since 1950s, fifty typhoons have hit Ningbo, caused 12 severe floods, and resulted in economic losses totalling an estimated RMB93 billion (Tang et al., 2015). Taken together, surges and astronomical tidal inundation in typhoons and storms period present challenges and risks to the city. Since 2015, the city joined the nation-led Sponge City Program (SCP) as one of the pilot cities, with an aim to raise stormwater protection capacity to handle storms at 1-in-30 years return period. Through retrofitting urban drainage system that aiming and constructing integral green-blue infrastructure in $80 \%$ of its urbanized area by the end of 2030 s (Chan et al., 2018; Tang et al., 2018; Qi et al., 2020;).

\subsection{Typhoon Fitow and In-Fa}

Typhoon "Fitow" made landfall on the $7^{\text {th }}$ October 2013 in Fuding (northern Fujian Province) that is located at the boundary between Fujian and Zhejiang Province, and influenced Ningbo severely. It affected over three million people in Zhejiang and produced prolonged intensive rainfalls and storm surges that were aligned with a second typhoon (Danas) right after Fitow. A rainfall of $263 \mathrm{~mm} / 24 \mathrm{hr}$ was recorded in the main urban districts of Ningbo including Yuyao, Fenghua, Yinzhou, Haizhu districts 
(Griffiths et al., 2019). Particularly, more than 100,000 properties in Yuyao district were inundated, and the economic loss was estimated at about RMB2 billion (at 2013 rate). The intensive rainfalls could not be discharged via the city's land drainage and the canal/river network because of the high level of river flow attributed to the high tide levels (Tang et al., 2015). Stormwater overtopped canal walls and caused severe pluvial floods (see Figure 2).

\subsection{Ningbo - background}

Ningbo is a typical coastal city located in the east coast of China (Figure 1), with immense annual rainfall ( $50 \%$ of the mean annual rainfall at about $1500 \mathrm{~mm}$ ) during typhoon season that runs from June to October annually. By contrast, rainfall in dry season (November to February) normally ranges from 250 to $300 \mathrm{~mm}$ annually. Water resources management in Ningbo focuses on not only the capacity of dams and reservoirs to prevent the outburst of dams under storms, but also the provision of adequate water resources during dry season (Griffiths et al., 2017). The majority of the city's $9816 \mathrm{~km}^{2}$ land area is flat, with elevation ranging from 2 to 10 metres above-sea-level, whereas the tidal range is from 1.6 to 5.8 metres. Traditionally, Ningbo is equipped with a land drainage system that can only handle rainfall events at 1 -in-1 to 1 -in-5 years return period. This means the city is at high risk during the typhoon period, as intensive stormwater is difficult to be discharged quickly through the drainage system and three tidal rivers (Yao River, Fenghua River, and Yong River), particularly when the surges are concurrently raising the river level to decrease the runoff capacities (Griffiths et al., 2020). Since 1950s, fifty typhoons have hit Ningbo, caused 12 severe floods, and resulted in economic losses totalling an estimated RMB93 billion (Tang et al., 2015). Taken together, surges and astronomical tidal inundation in typhoons and storms period present challenges and risks to the city. Since 2015, the city joined the nation-led Sponge City Program (SCP) as one of the pilot cities, with an aim to raise stormwater protection capacity to handle storms at 1-in-30 years return period. Through retrofitting urban drainage system that aiming and constructing integral green-blue infrastructure in $80 \%$ of its urbanized area by the end of 2030 s (Chan et al., 2018; Tang et al., 2018; Qi et al., 2020;).

\subsection{Typhoon Fitow and In-Fa}

Typhoon "Fitow" made landfall on the $7^{\text {th }}$ October 2013 in Fuding (northern Fujian Province) that is located at the boundary between Fujian and Zhejiang Province, and influenced Ningbo severely. It affected over three million people in Zhejiang and produced prolonged intensive rainfalls and storm surges that were aligned with a second typhoon (Danas) right after Fitow. A rainfall of $263 \mathrm{~mm} / 24 \mathrm{hr}$ was recorded in the main urban districts of Ningbo including Yuyao, Fenghua, Yinzhou, Haizhu districts (Griffiths et al., 2019). Particularly, more than 100,000 properties in Yuyao district were inundated, and the economic loss was estimated at about RMB2 billion (at 2013 rate). The intensive rainfalls could not be discharged via the city's land drainage and the canal/river network because of the high level of river flow attributed to the high tide levels (Tang et al., 2015). Stormwater overtopped canal walls and caused severe pluvial floods (see Figure 2). 


\section{Three Keys To Improving "resilience" During And After "in-fa"}

\subsection{Good "Preparation"}

Typhoon In-Fa has brought torrential downpours to Ningbo and the region across Zhejiang and a few neighbourhood provinces. Particularly, Ningbo was facing coactive effects of "rainfalls", "tides" and "wind" according to the China Meteorological Administration (PHYS, 2021). The municipal government was well prepared, through identifying high-risk areas (such as hilly and low-lying flood prone zones) and issuance warnings periodically. Major airports and transport hubs were shut down and public were persuaded to stay at safe places (Chen and Yang, 2021). Moreover, timely relocation service was executed to evacuate communities from "high risk" areas to temporary shelters (such as sports halls, schools and community service centres, etc.), where basic essentials were provided, including cup noodles, hot water, bathing places, toilet, air conditions and even televisions. Affected residents can stay at these places free-of-charge until the event was completely over $(\mathrm{Hu}, 2021)$. During In-Fa, more than 421,000 residents were relocated before severe impacts occurred. This is key to ensuring "zero casualties" in this fierce typhoon event.

\subsection{Smart technologies helped to build effective "Response"}

The importance of social media and technologies such as "Big Data" and "Smart Technologies" has been recognised by the municipal government to disseminate warnings through a joint public-private partnership, and ensure effective public-private communication before, during and after the typhoon event (Zhou, 2021). Ningbo municipal government worked closely with mobile companies to collect and analyse big data, disseminate information effectively through artificial intelligence, and $5 \mathrm{G}$ e-platform. Particularly, social media can update users with real-time information such as disruptions of services caused by flooding (e.g. disrupted roads) and high-risk areas. Social media also helped accelerating the responses from the emergency services (e.g. police, fire services, army, ambulances and medical services) (BendiBao, 2021). 3D mapping services helped the governmental agencies to identify inundated communities (e.g. Dongqiao town), specify safe rescue routes for providing essential services (e.g. water, food, etc.) (Tieshou, 2021). Social media users also volunteered to urge the public to prepare power bank in case of power outage during the typhoon and flooding period, as understood the importance of mobile phones and smart technologies in receiving information and seeking assistance when needed (WeChat, 2021). We have yet to finalise an assessment of social media in this event. Nevertheless, according to Weibo (an e-platform) data, we have found there are over 2.45 billion times discussions about this typhoon event regarding awareness, preparation and governmental responses, which demonstrated the vital importance of social media in building resilience and minimising damages.

\subsection{Supportive, helpful and caring "Recovery"}

A key lesson learnt from typhoon Fitow in October 2013 was how to reduce economic loss, which was estimated to be as high as 33 billion RMB (Sina News., 2021), which stressed the need to establish a systematic and adequate flood insurance programme, an essential practice to reduce households' 
financial risks associated with their properties and assets. An encouraging news is that in association with Typhoon In-Fa event, the insurers (such as insurance companies, re-insurance companies and banks) are improving their services through e-platform and smart technologies (Li, 2021). For example, relying online document submission and scrutiny, the handling processes was speed up and insured clients can get financial compensation within 20 minutes (Chen, 2021).

Additionally, municipal government worked very hard to ensure affected communities getting adequate supports via a supportive, helpful, caring and speedy recovery processes, such as public infrastructure improvement (sorting out road damages, retain public transport), adequate food supply, water and sanitation services (Dominique and Sophie, 2021). Also with enhancement of public perception, participation and post-disaster' education (via schools, universities and communities), so that residents could recover from typhoon and resume their normal life effectively.

\section{Concluding remarks - Moving towards "Coastal Resilient Cities"}

Practices focusing on preparation, prevention and recovery ensured "zero causalities" and a significant reduction in economic loss of the In-Fa event, for example, Ningbo's Cixi district suffered a RMB2.03 billion loss at Fitow, but only RMB 0.19 billion from In-Fa (Wen, 2021). The success of Ningbo municipal government and all stakeholders are truly champions. The lessons learnt from Fitow and successful experience of In-Fa in Ningbo city could be heeded in typhoon/flood governance of other Chinese and Asian coastal cities. Urban resilience can be improved by integrating flood "Preparation", emergency "Responses" and post-disaster "Recovery" into a city's long-term development plans, such as "Master Plan" and "Climate Action Plan". Particularly, these practices should also be merged with the nation's "Sponge City" Program, which prioritizes grey-blue-green infrastructure but obviously lacks the social dimension, which is urgently needed in light of hectic "Sponge City" construction and climatic uncertainties.

\section{Declarations}

\section{Acknowledgement}

This study was funded by the National Key R\&D Program of China (Grant Number: 2019YFC1510400) and the National Science Foundation Program of China (Grant Number: NSFC41850410497); the Institute of Asia Pacific Studies (IAPS) research funds and the postgraduate research fund at University Nottingham Ningbo China; Guizhou Science and Technology Planning of Project (Grant number: 2019 2879).

Funding (information that explains whether and by whom the research was supported)

This study was funded by the National Key R\&D Program of China (Grant Number: 2019YFC1510400) and the National Science Foundation Program of China (Grant Number: NSFC41850410497); the Institute of Asia Pacific Studies (IAPS) research funds and the postgraduate research fund at University 
Nottingham Ningbo China; Guizhou Science and Technology Planning of Project (Grant number: 2019 2879).

Conflicts of interest/Competing interests (include appropriate disclosures)

We can confirm that manuscript has no conflicts of interest and competing interests issues

Availability of data and material (data transparency)

Not applicable

Code availability (software application or custom code)

Not applicable

Authors' contributions (optional: please review the submission guidelines from the journal whether statements are mandatory)

Faith Ka Shun Chan is the lead author who had the idea for the article and performed the literature search and data analysis; and drafted up this short communication manuscript. Other co-authors performed the literature search, data analysis and critically revised the manuscript.

Ethics approval (include appropriate approvals or waivers)

Not applicable as that is the review manuscript only.

Consent to participate (include appropriate statements)

On behalf of all co-authors, we would like to state all information provided above in the declarations are true and correct.

Consent for publication (include appropriate statements)

On behalf of all co-authors, we would like to state all information provided above in the declarations are true and correct.

\section{References}

BendiBao (2021) Water level real-time update for Typhoon In-Fa Ningbo in 2021 (2021)

http://m.nb.bendibao.com/mip/64214.shtm. Cited August 12021

Chan FKS, Griffiths JA, Higgitt D, Xu S, Zhu F, Tang Y-T, Xu Y, Thorne CR (2018) "Sponge City" in China-A breakthrough of planning and flood risk management in the urban context. Land Use Policy 76: 772-778 DOI 10.1016/j.landusepol.2018.03.005 
Chan FKS, Yang LE, Scheffran J, Mitchell G, Adekola O, Griffiths J, Chen Y, Li G, Lu X, Qi Y, Li L, Zheng H, McDonald A (2021) Urban flood risks and emerging challenges in a Chinese delta: The case of the Pearl River Delta. Environmental Science \& Policy 122: 101-115 DOI 10.1016/j.envsci.2021.04.009

Chan HK, Dai J, Wang X, Lacka E (2019) Logistics and supply chain innovation in the context of the Belt and Road Initiative (BRI). Transportation Research Part E: Logistics and Transportation Review 132: 51-56 DOI 10.1016/j.tre.2019.10.009

Local officials persuaded residents to emergently move in Cicheng Ningbo in China (2021) https://baijiahao.baidu.com/s?id=1706170734132612179\&wfr=spider\&for=pc. Cited July 312021

The insurance industry of Ningbo received 7,400 reports because of typhoon; and more than half of vehicle damages were reported. (2021) https://xw.qq.com/partner/vivoscreen/20210726A08KHV/20210726A08KHV00? showComments=0\&isNews=1. Cited August 12021

Church JA, White NJ (2011) Sea-Level Rise from the Late 19th to the Early 21st Century. Surveys in Geophysics 32: 585-602 DOI 10.1007/s10712-011-9119-1

Shanghai Region Braces for Typhoon In-Fa After Flooding in Central China (2021) https://www.usnews.com/news/world/articles/2021-07-25/east-china-braces-for-typhoon-in-fa-afterflooding-in-countrys-centre. Cited July 262021

Griffiths J, Chan FKS, Shao M, Zhu F, Higgitt DL (2020) Interpretation and application of Sponge City guidelines in China. Philos Trans A Math Phys Eng Sci 378: 20190222 DOI 10.1098/rsta.2019.0222

Griffiths JA, Chan FKS, Zhu F, Wang V, Higgitt DL (2017) Reach-scale variation surface water quality in a reticular canal system in the lower Yangtze River Delta region, China. J Environ Manage 196: 80-90 DOI 10.1016/j.jenvman.2017.02.079

Griffiths JA, Zhu F, Chan FKS, Higgitt DL (2019) Modelling the impact of sea-level rise on urban flood probability in SE China. Geoscience Frontiers 10: 363-372 DOI 10.1016/j.gsf.2018.02.012

Hallegatte S, Green C, Nicholls RJ, Corfee-Morlot J (2013) Future flood losses in major coastal cities. Nature Climate Change 3: 802-806 DOI 10.1038/nclimate1979

Against the typhoon 144 hours, Ningbo's public security 'hardcore' adhering (2021) https://new.qq.com/omn/20210727/20210727A08U6I00.html. Cited July 302021

Typhoon In-Fa lands in Zhejiang, moves northward (2021) http://www.ecns.cn/news/2021-07-26/detailihapphqa4402469.shtml. Cited August 22021

Fighting In-Fa, the insurance strengthed the technical response ability to natural disasters (2021) https://baijiahao.baidu.com/s?id=1706316720372423412\&wfr=spider\&for=pc. Cited August 12021 
Typhoon weakens after 2nd landfall in Zhejiang (2021)

http://www.chinadaily.com.cn/a/202107/27/WS60ff3cdba310efa1bd6647b0.html. Cited August 12021

Nerem RS, Beckley BD, Fasullo JT, Hamlington BD, Masters D, Mitchum GT (2018) Climate-change-driven accelerated sea-level rise detected in the altimeter era. Proc Natl Acad Sci U S A 115: 2022-2025 DOI $10.1073 /$ pnas. 1717312115

$1003 \mathrm{~mm}$ ! Typhoon In-Fa broke the Zhejiang provincial record! (2021) https://new.qq.com/omn/20210726/20210726A0EYDZ00.html. Cited August 22021

Typhoon In-Fa drenches eastern China (2021) https://phys.org/news/2021-07-east-china-battenstyphoon-in-fa.html. Cited July 262021

Qi Y, Chan FKS, O'Donnell EC, Feng M, Sang Y, Thorne CR, Griffiths J, Liu L, Liu S, Zhang C, Li L, Thadani D (2021) Exploring the Development of the Sponge City Program (SCP): The Case of Gui'an New District, Southwest China. Frontiers in Water 3 DOI 10.3389/frwa.2021.676965

Qi Y, Chan FKS, Thorne C, O’Donnell E, Quagliolo C, Comino E, Pezzoli A, Li L, Griffiths J, Sang Y, Feng M (2020) Addressing Challenges of Urban Water Management in Chinese Sponge Cities via Nature-Based Solutions. Water 12 DOI 10.3390/w12102788

The typhoon has not gone! How to settle a claim to catastrophe insurance? (2021) https://k.sina.cn/article_7505202169_1bf584bf902000ww34.html?wm=13500_0055\&vt=4. Cited August 12021

Tang Y-T, Chan FKS, Griffiths J (2015) City profile: Ningbo. Cities 42: 97-108 DOI 10.1016/j.cities.2014.10.001

Tang YT, Chan FKS, O'Donnell EC, Griffiths J, Lau L, Higgitt DL, Thorne CR (2018) Aligning ancient and modern approaches to sustainable urban water management in China: Ningbo as a "Blue-Green City" in the "Sponge City" campaign. Journal of Flood Risk Management 11 DOI 10.1111/jfr3.12451

The Dongqiao Town was totally submerged (2021) https://720yun.com/t/4avktbi7zpq? scene_id=77254202. Cited April 302021

Verheggen B, Strengers B, Cook J, van Dorland R, Vringer K, Peters J, Visser H, Meyer L (2014) Scientists' Views about Attribution of Global Warming. Environmental Science \& Technology 48: 8963-8971 DOI 10.1021/es501998e

Wang X (2018) Flooding Hazards and Risk Analysis in the Pearl River Delta, China Springer, Switzerland, pp. 185-212.

Typhoon In-Fa (2021) https://www.wunderground.com/hurricane/western-pacific/2021/typhoon-in-fa. Cited July 272021 
Ningbo residents in flooding area are in urgent need of charging battery, please lend a helping hand! (2021) https://mp.weixin.qq.com/s/N4UlHvxU6mxgECj4e6g8EQ. Cited July 292021

More rain caused economic loss more thant 90\%! How Cixi did it? (2021)

https://zj.zjol.com.cn/news.html?id=1704706. Cited August 32021

Woo WC, Wong WT (2010) Sea-level change - observations, causes and impacts Hong Kong, HongKong.

Shanghai braces for Typhoon In-Fa (2021)

http://www.chinadaily.com.cn/a/202107/25/WS60fce17ca310efa1bd6642a1.html. Cited August 12021

Figures

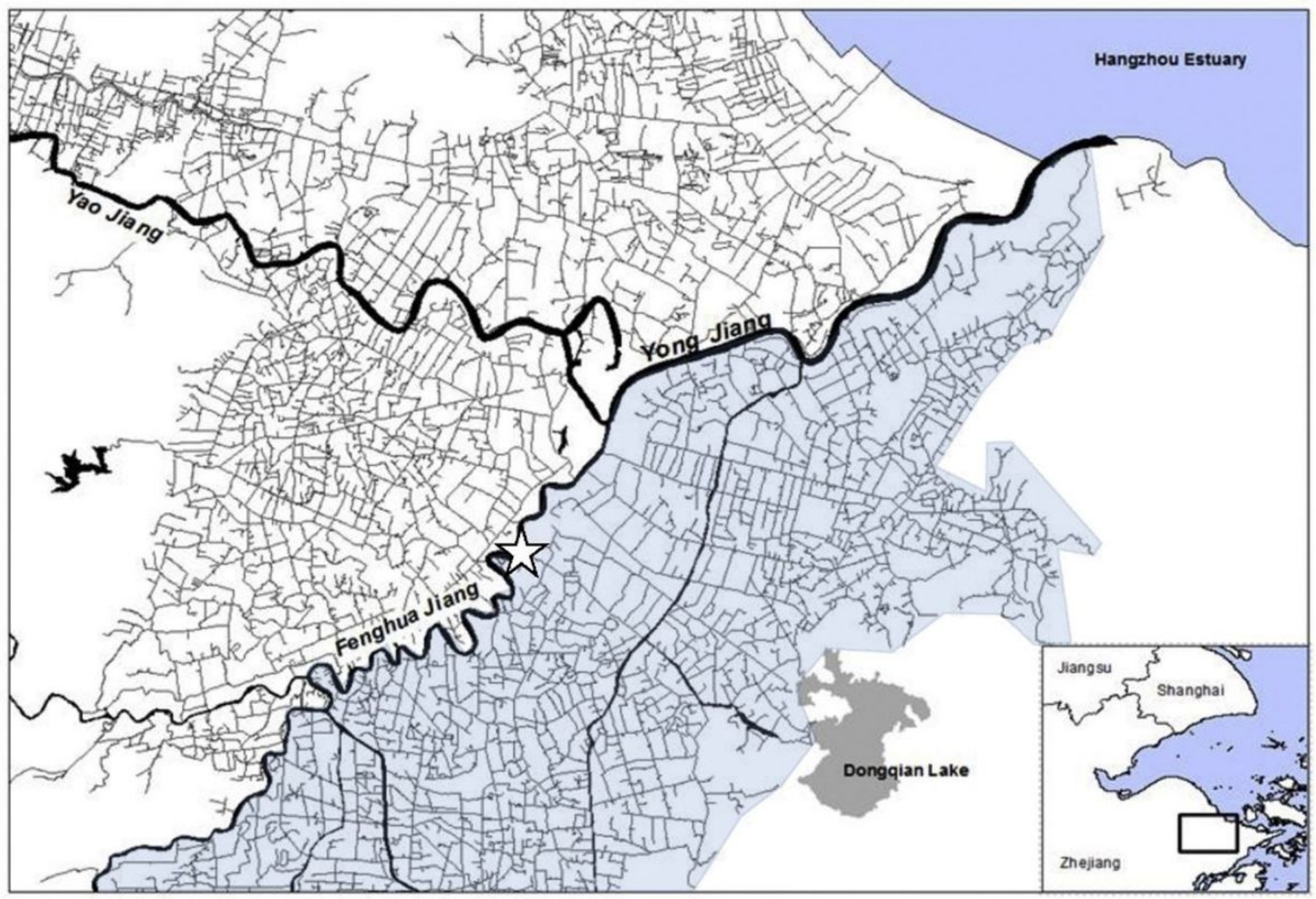

Figure 1

Location of Ningbo City, Zhejiang Province, southeast China (shaded area indicates modelled drainage network, and indicates location of rainfall and canal-level gauge data) (Source: Griffiths et al., 2019). 


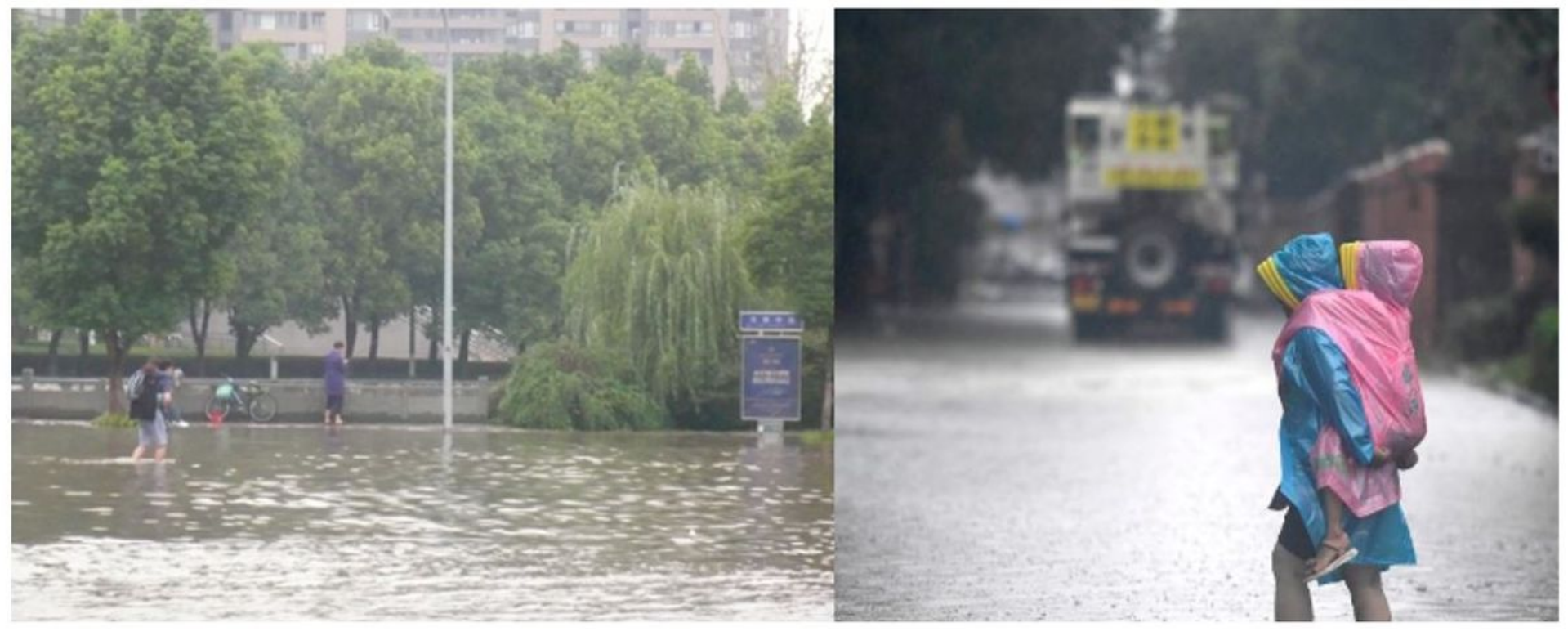

Figure 2

Typhoon Fitow brought pluvial flood on 7 October in Yinzhou District (left), Typhoon In-Fa brought pluvial flood on 26 July 2021 (right) Sources: author and Ningbo Municipal Government (with permission to use) 